\title{
Effects of vitamin D supplementation on androgens in men with low testosterone levels: a randomized controlled trial
}

\author{
Elisabeth Lerchbaum ${ }^{1} \cdot$ Christian Trummer $^{1} \cdot$ Verena Theiler-Schwetz $^{1} \cdot$ Martina Kollmann $^{2} \cdot$ Monika Wölfler $^{2}$. \\ Annemieke C. Heijboer ${ }^{3,4} \cdot$ Stefan Pilz $^{1} \cdot$ Barbara Obermayer-Pietsch $^{1}$
}

Received: 7 August 2018 / Accepted: 4 November 2018 / Published online: 20 November 2018

(c) The Author(s) 2018

\begin{abstract}
Purpose It has been hypothesized that vitamin D is associated with androgen levels in men. We, therefore, aimed to evaluate whether vitamin D supplementation increases serum total testosterone (TT) levels in men with low TT levels at baseline.

Methods The Graz Vitamin D\&TT-RCT is a single-center, double-blind, randomized placebo-controlled trial conducted between March 2013 and November 2017 at the endocrine outpatient clinic at the Medical University of Graz, Austria. One-hundred healthy men with serum TT levels $<10.4 \mathrm{nmol} / 1$ and 25 -hydroxyvitamin D [25(OH)D] levels $<75 \mathrm{nmol} / 1$ participated in the trial. Subjects were randomized to receive 20,000 IU of vitamin D3/week $(n=50)$ or placebo $(n=50)$ for 12 weeks. Primary outcome was TT measured using mass spectrometry. Secondary outcomes were free testosterone, free androgen index, sex hormone-binding globulin, estradiol, follicle-stimulating hormone, luteinizing hormone, metabolic characteristics, and body composition.

Results Ninety-four men [mean age and 25(OH)D: $47( \pm 12)$ years and $56.3( \pm 18.3)$ nmol/l, respectively] completed the study. We found no significant treatment effect on serum TT or on the remaining secondary outcome variables.

Conclusion Vitamin D treatment had no effect on serum TT levels in middle-aged healthy men with low TT levels.
\end{abstract}

Keywords Vitamin D $\cdot$ Testosterone $\cdot$ Randomized controlled trial $\cdot$ SHBG $\cdot$ Androgens

\section{Introduction}

Vitamin D is well known for its role in maintaining calcium homeostasis and promoting bone mineralization [1]. Considering the high prevalence of an insufficient vitamin D status in many populations as well as the potential link

Elisabeth Lerchbaum

Elisabeth.lerchbaum@medunigraz.at

1 Division of Endocrinology and Diabetology, Department of Internal Medicine, Medical University of Graz, Auenbruggerplatz 15, $8036 \mathrm{Graz}$, Austria

2 Division of Gynecological Endocrinology and Reproductive Medicine, Department of Obstetrics and Gynecology, Medical University of Graz, Auenbruggerplatz 14, 8036 Graz, Austria

3 Endocrine Laboratory, Department of Clinical Chemistry, VU University Medical Center, De Boelelaan 1117, 1081 HV Amsterdam, The Netherlands

4 Laboratory of Endocrinology, Academic Medical Center, Meibergdreef 9, 1105 AZ Amsterdam, The Netherlands between low vitamin $D$ status and adverse health outcomes [2], vitamin D deficiency is classified as an important public health problem [1]. Beyond the association between vitamin D deficiency and musculoskeletal diseases, evidence is accumulating that vitamin D deficiency is also a risk marker for insulin resistance [3], cardiovascular disease [4], infectious and autoimmune diseases [2], cancer [5] as well as increased mortality [1]. Likewise, low testosterone levels in men are related to adverse events including increased cardiovascular and all-cause mortality [6-9]. As men with combined androgen and vitamin D deficiencies are at high risk for mortality, a parallel deficiency of both hormones has been suggested to be a marker of poor overall health [10]. Therefore, a causal relationship between vitamin $\mathrm{D}$ and testosterone [11] is of high clinical interest. In particular, a potential increase of testosterone levels after vitamin D treatment might be important.

Testosterone is produced in the Leydig cells following pituitary pulsatile LH secretion. Its production is also modulated by paracrine and autocrine signals supplied by growth factors and cytokines secreted within the testis $[12,13]$. The 
vitamin D receptor (VDR) is almost ubiquitously expressed in human cells, which underlines the clinical significance of the vitamin D endocrine system [1, 2, 14]. VDR- and vitamin D-metabolizing enzymes are concomitantly expressed in the entire reproductive male tract, including Leydig cells [15]. Further, vitamin D significantly increased testosterone production in a human primary testicular cell culture model [11]. Therefore, vitamin D might be involved in the production of male reproductive hormones.

Observational studies have, by the majority, shown that vitamin D deficiency is associated with low testosterone concentrations [16]. In contrast, data from randomized controlled trials (RCTs) on vitamin D supplementation and testosterone status have consistently shown no statistically significant effect of vitamin D vs. placebo regarding testosterone levels [16]. Likewise, we failed to find a significant effect of vitamin D treatment on androgen levels in healthy men with normal total testosterone (TT) levels participating in the Graz Vitamin D\&TT-RCT, a RCT recruiting 100 men with normal serum TT concentrations and 100 men with low serum TT concentrations [17].

In this manuscript, we present results from men with low serum TT levels who participated in the Graz Vitamin D\&TT-RCT but required longer recruitment time compared to men with normal serum TT concentrations thus resulting in two separate publications. To our knowledge, this is the first RCT specifically designed to analyze vitamin D effects on androgen levels in men with low baseline serum TT levels.

\section{Methods}

\section{Study design}

We present the results of the second arm (involving men with low serum TT levels) of the Graz Vitamin D\&TT-RCT, a single-center, double-blind, placebo-controlled, parallelgroup study performed at the Medical University of Graz, Austria. The trial was designed to investigate the effect of vitamin D supplementation (12 weeks) on serum TT levels in men. The methods and study design have been published in detail previously [17]. The design, conduction and publication of this study adhere to the recommendations of the CONSORT Statement (http://www.consort-statement. org/). The trial was registered at http://www.clinicaltrialsr egister.eu (EudraCT number, 2011-003575-11) and at clinicaltrials.gov (ClinicalTrials.gov Identifier NCT01748370). The study protocol was approved by the ethics committee of the Medical University of Graz (EK 23-513 ex 10/11) and written informed consent was obtained from each participant before entering the study.
The Graz Vitamin D\&TT-RCT examines vitamin D effects in 100 men with normal serum TT levels (results have been published previously [17]) as well in 100 men with low serum TT levels (data presented in this manuscript).

\section{Subjects}

Eligible study participants were men aged $\geq 18$ and $<70$ years with 25 -hydroxyvitamin D [25(OH)D] levels $<75 \mathrm{nmol} / 1$ and serum TT levels $<10.4 \mathrm{nmol} / 1$. Exclusion criteria were hypercalcemia (defined as a serum calcium $>2.65 \mathrm{mmol} / \mathrm{l}$ ), oral or transdermal testosterone supplementation in the last 2 months before entering the study, intramuscular testosterone supplementation 6 months before entering the study, regular intake of vitamin D supplements before study entry, chronic diseases (such as diabetes mellitus), thyroid disease, endocrine disturbances in need of treatment (such as pituitary disorders), history of hypogonadisms or known diseases associated with hypogonadism (except obesity) or diseases known to interfere with vitamin D intake or sensitive to vitamin D intake (including inflammatory diseases with granuloma such as sarcoidosis, tuberculosis, Wegener's granulomatosis; including other forms of vasculitis and inflammatory bowel diseases), intake of medication influencing metabolic or endocrine parameters (insulin sensitizers, insulin, or glucocorticoids) in the last 3 months before study entry; PSA $>4 \mathrm{ng} / \mathrm{ml}$ (or $>3 \mathrm{ng} / \mathrm{ml}$ in men at high risk for prostate cancer), palpable prostate nodule or induration, hematocrit $>50 \%$, untreated severe obstructive sleep apnea, severe lower urinary tract symptoms, uncontrolled or poorly controlled heart failure, a history of prostate cancer, breast cancer, orchidectomy, and chromosomal disorders (e.g. Klinefelter Syndrome). Men were recruited from the outpatient clinic of the Department of Internal Medicine, Division of Endocrinology and Diabetology, and the outpatient clinic of the Department of Urology, Medical University of Graz, Austria, as well as from male hospital staff and male family members of hospital staff. Men were informed about the trial either by a conversation in the outpatient clinic, by written information posted in the respective outpatient clinics or by a telephone call. All patients were informed that participation in the study is voluntary and that refusal to participate as well as stopping at any time without giving reasons, without any consequences is possible. Written informed consent was obtained before carrying out any study-related procedures from all subjects who participated in the study.

\section{Intervention}

Subjects were allocated to the vitamin D or placebo group according to a computer-generated randomization list using a ratio of 1:1. Study medication was placed into numbered 
bottles according to this computer-generated randomization list. Randomization procedures were conducted using a web-based software (http://www.randomizer.at/) with GCP compliance as confirmed by the Austrian Agency for Health and Food Safety (AGES).

The treatment group received an oral dose of 20,000 IU vitamin D weekly (equivalent to 2857 IU/day) as 50 oily drops weekly (Oleovit D3-drops; Fresenius Kabi Austria $\mathrm{GmbH}, \mathrm{Linz}$ ) for 12 weeks and the placebo group received 50 oily drops without vitamin D for 12 weeks. Placebo oil contained the same oil as Oleovit D3-drops (without vitamin D content) and was delivered by Fresenius Kabi Austria $\mathrm{GmbH}$, Linz. All investigators who enrolled participants, collected data, and assigned intervention were masked to participant allocation.

To improve and verify compliance, patients were asked to return the study medication bottles (full as well as empty bottles) at study end (visit 3 ).

\section{Primary outcome}

The primary outcome was the change in serum TT levels after 12 weeks of vitamin D supplementation compared to placebo.

\section{Secondary outcomes}

The secondary outcome was the change in endocrine parameters including free testosterone (FT), free androgen index (FAI), sex hormone-binding globulin (SHBG), follicle-stimulating hormone (FSH), luteinizing hormone (LH) and estradiol after vitamin D supplementation compared to placebo.

Further pre-specified secondary outcomes included changes in metabolic parameters (area under the curve (AUC)glucose, and AUCinsulin, insulin resistance, insulin sensitivity, serum lipids), body composition (fat mass and lean mass) as well as sexual, psychological, and physical symptoms after vitamin D supplementation (assessed at baseline and after 12 weeks).

There was no change in study outcomes after the trial had commenced. Although pre-specified as secondary outcome, sexual, psychological, and physical symptoms were assessed only at baseline, as we were not able to document these data at study end due to organizational problems.

Further, we performed subgroup analyses of primary and secondary endpoints in study participants with serum 25-hydroxyvitamin D levels $<50 \mathrm{nmol} / \mathrm{l}$ at baseline (not pre-specified).

\section{Procedures}

Basal blood samples for 25(OH)D, PTH, TT, SHBG, LH, FSH, estradiol, glucose, insulin, lipids, and calcium were collected between 8.00 and 9.00 a.m. after an overnight fast. $25(\mathrm{OH}) \mathrm{D}$ and TT measured by immunoassays were used for evaluation of inclusion criteria. Biobanking of remaining blood samples was performed by freezing and storing at $-80{ }^{\circ} \mathrm{C}$ until analysis. Serum levels of $25(\mathrm{OH}) \mathrm{D}$ and TT were additionally measured by well-adjusted isotopedilution liquid chromatography-tandem mass spectrometry (ID-LC-MS/MS) methods in 2018 [18, 19]. 25(OH)D and TT measured by ID-LC-MS/MS were used for statistical analyses. FT values were calculated from TT (measured by ID-LC-MS/MS), SHBG, and albumin according to Vermeulen [20]. The FAI was calculated as TT (measured by ID-LC-MS/MS $)(\mathrm{nmol} / \mathrm{l}) / \mathrm{SHBG}(\mathrm{nmol} / \mathrm{l}) \times 100$.

Details on procedures and laboratory measurements have been published previously [17].

\section{Statistical analyses}

Details on sample size calculation have been published previously [17].

Continuous data are presented as median with interquartile range and categorical data are presented as percentages. The distribution of data was analyzed by descriptive statistics and Kolmogorov-Smirnov test. Skewed variables were $\log$ transformed and rechecked for normal distribution. Student's $T$ test was used for comparisons of baseline characteristics between the vitamin $\mathrm{D}$ and the placebo group. Analyses of primary and secondary outcome variables were performed according to the intention-to-treat principle and inclusion of all participants with baseline and follow-up values. Analysis of covariance with adjustments for baseline values was applied to test for differences in the primary and secondary outcome variables between the treatment and the placebo group at study end. All statistical procedures were performed with SPSS version 23 (SPSS Inc., Chicago, IL, USA). A $p$ value $<0.05$ was considered statistically significant.

\section{Results}

We took blood samples from approximately 600 men and analyzed 25(OH)D concentrations and TT concentrations (Fig. 1). Men with serum TT levels $<10.4 \mathrm{nmol} / \mathrm{l}, 25(\mathrm{OH})$ D levels $<75 \mathrm{nmol} / \mathrm{l}$, and a medical history without any exclusion criteria were informed about the study, its purpose, potential benefits, and possible risks, and were invited to participate in the trial. Main reasons for exclusion were serum TT $\geq 10.4 \mathrm{nmol} / \mathrm{l}, 25(\mathrm{OH}) \mathrm{D}$ levels $>75 \mathrm{nmol} / \mathrm{l}$, as well as refusal to participate. One-hundred men who met all inclusion as well as no exclusion criteria and gave their written informed consent were randomized and enrolled in the study. The first subject was randomized in March 2013 
Fig. 1 Study flow chart representing recruitment, drop-out, and follow-up of study participants. TT total testosterone, 25( OH)D 25-hydroxyvitamin D, T2DM type 2 diabetes mellitus

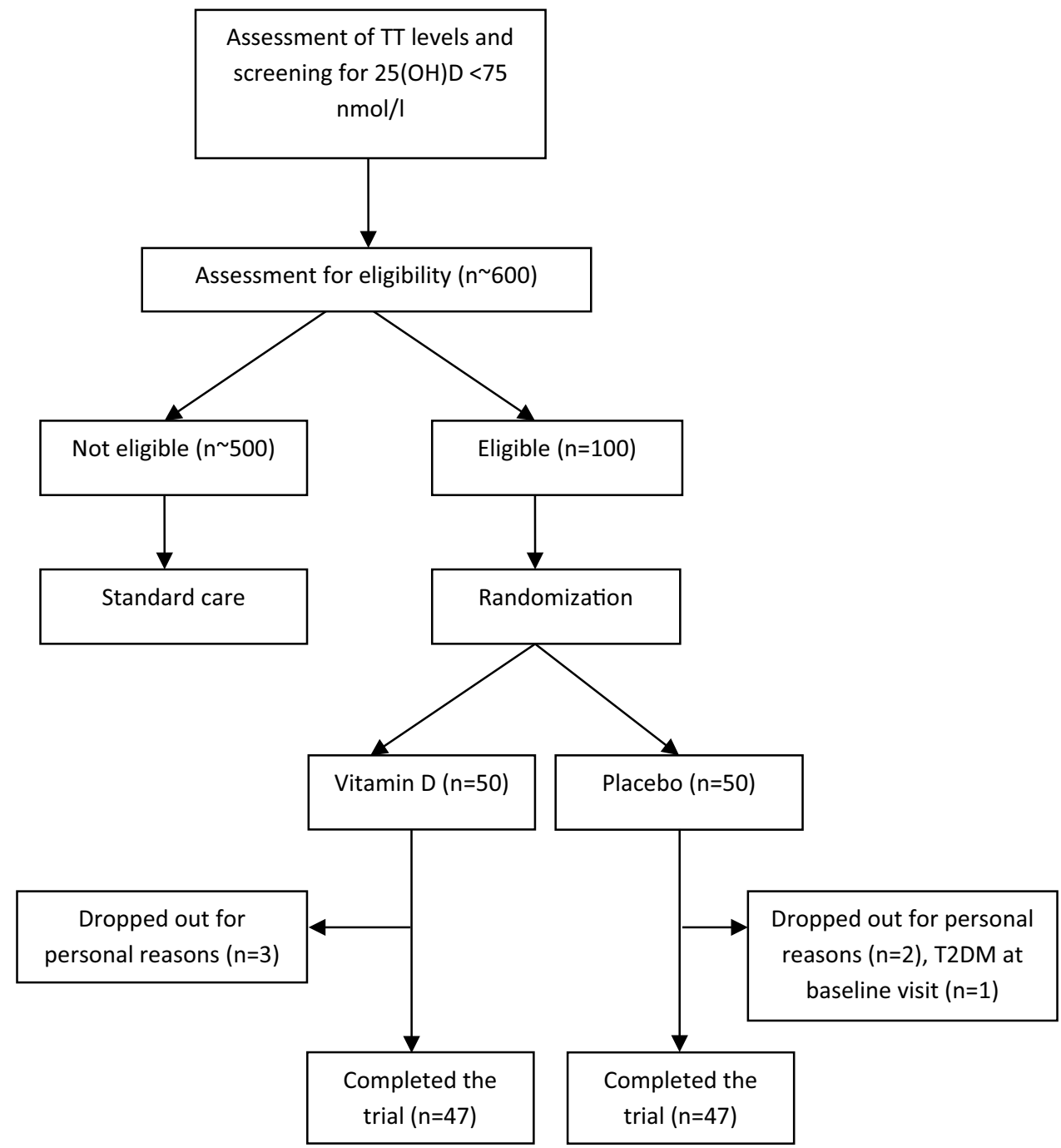

and the last follow-up was performed in November 2017. Baseline characteristics of all study participants are shown in Table 1. We found no significant difference in baseline characteristics between the vitamin D and the placebo group. The mean overall treatment period was $84 \pm 4$ days in the vitamin $\mathrm{D}$ and $85 \pm 7$ days in the placebo group $(p=0.809)$. A total of 94 men completed the study (Fig. 1) and were analyzed for primary and secondary outcomes.

\section{Primary and secondary outcome variables}

We show results of analyses of primary and secondary outcomes at study end in Table 2 . We found no significant treatment effect on primary and secondary outcome variables.

\section{Subgroup analyses}

Baseline characteristics of study participants with baseline $25(\mathrm{OH}) \mathrm{D}$ concentrations $<50 \mathrm{nmol} / \mathrm{l}(n=39)$ are shown in
Table 3. We found no significant difference in baseline characteristics between the vitamin D and the placebo group in this subgroup. We observed a significant increase in SHBG levels after 12 weeks in the placebo group, whereas SHBG levels remained unchanged in the vitamin D group (Table 4). We observed no significant treatment effect on serum TT and the remaining secondary outcome variables (Table 4).

\section{Mineral metabolism}

Parameters of mineral metabolism at study end in all study participants and in study participants with baseline $25(\mathrm{OH})$ $\mathrm{D}$ concentrations $<50 \mathrm{nmol} / 1$ are shown in Tables 5 and 6 , respectively. We found a significant treatment effect on $25(\mathrm{OH}) \mathrm{D}$ levels at study end in both groups. We observed no significant treatment effect on $\mathrm{PTH}$, serum calcium or urine calcium levels in both groups.

During the study, we observed no important harms or unintended treatment effects. No study participant treated 
Table 1 Baseline characteristics of study participants

\begin{tabular}{|c|c|c|c|c|c|c|c|}
\hline & \multicolumn{2}{|c|}{$\begin{array}{l}\text { All study participants } \\
(n=100)\end{array}$} & \multicolumn{2}{|c|}{ Vitamin $\mathrm{D}(n=50)$} & \multicolumn{2}{|c|}{ Placebo $(n=50)$} & \multirow[t]{2}{*}{$p$ value } \\
\hline & Median & IQR & Median & IQR & Median & IQR & \\
\hline Age (years) & 49 & $39-56$ & 48 & $37-56$ & 50 & $41-58$ & 0.505 \\
\hline BMI $\left(\mathrm{kg} / \mathrm{m}^{2}\right)$ & 28.6 & $25.9-32.4$ & 28.4 & $25.9-31.6$ & 29.4 & $25.6-34.2$ & 0.534 \\
\hline 25-Hydroxyvitamin D (nmol/l) & 54 & $43-69$ & 56 & $44-72$ & 53 & $42-63$ & 0.799 \\
\hline PTH (pg/ml) & 45.4 & $35.8-56.4$ & 45.4 & $35.2-58.0$ & 43.1 & $36.3-55.2$ & 0.460 \\
\hline Serum calcium (mmol/l) & 2.37 & $2.32-2.43$ & 2.37 & $2.32-2.44$ & 2.36 & $2.32-2.42$ & 0.328 \\
\hline Urine calcium (mmol/l) & 2.66 & $1.30-3.63$ & 2.50 & $1.19-3.61$ & 2.83 & $1.50-3.63$ & 0.513 \\
\hline Total testosterone $\mathrm{a}^{\mathrm{a}}(\mathrm{nmol} / \mathrm{l})$ & 12.7 & $10.6-15.9$ & 12.7 & $10.5-15.4$ & 13.2 & $10.7-16.0$ & 0.869 \\
\hline Total testosterone immunoassay $(\mathrm{nmol} / \mathrm{l})^{\mathrm{b}}$ & 8.2 & $6.9-9.3$ & 8.0 & $6.8-9.1$ & 8.4 & $7.0-9.6$ & 0.191 \\
\hline Free testosterone (ng/ml) & 0.078 & $0.057-0.094$ & 0.080 & $0.058-0.092$ & 0.075 & $0.053-0.09$ & 0.798 \\
\hline SHBG (nmol/l) & 28.9 & $22.9-41.5$ & 27.2 & $20.3-41.5$ & 30.4 & $24.0-41.5$ & 0.559 \\
\hline Free Androgen Index & 44.3 & $30.2-58.9$ & 44.4 & $32.5-56.7$ & 40.8 & $28.8-61.9$ & 0.859 \\
\hline Estradiol (ng/ml) & 34.7 & $26.9-43.0$ & 34.7 & $26.9-44.2$ & 34.7 & $26.2-42.8$ & 0.765 \\
\hline $\mathrm{FSH}(\mathrm{mU} / \mathrm{ml})$ & 5.0 & $3.4-7.6$ & 5.0 & $3.9-6.8$ & 5.5 & $3.3-7.9$ & 0.072 \\
\hline LH (mU/ml) & 3.7 & $2.7-5.5$ & 3.7 & $2.6-5.0$ & 3.8 & $2.9-5.7$ & 0.259 \\
\hline HOMA-IR & 3.0 & $2.0-4.8$ & 3.0 & $1.9-4.4$ & 3.1 & $2.1-5.4$ & 0.387 \\
\hline НОМА- $\beta$ & 165.3 & $114.7-237.3$ & 160.1 & $113.8-229.9$ & 184.6 & $115.5-241.4$ & 0.138 \\
\hline MATSUDA-index & 3.7 & $2.2-6.2$ & 3.5 & $2.2-5.3$ & 3.9 & $2.0-7.4$ & 0.242 \\
\hline QUICKI & 0.32 & $0.30-0.34$ & 0.32 & $0.31-0.35$ & 0.32 & $0.30-0.34$ & 0.381 \\
\hline AUCglucose & 258.5 & $223.0-299.3$ & 261.5 & $233.8-304.5$ & 251.0 & $217.8-299.3$ & 0.310 \\
\hline AUCinsulin & 129 & $74.6-243.5$ & 126.8 & $84.9-232.2$ & 136.0 & $66.8-253.6$ & 0.282 \\
\hline Total cholesterol (mg/dl) & 211 & $178-237$ & 204 & $164-236$ & 216 & $192-237$ & 0.212 \\
\hline HDL-C (mg/dl) & 50 & $41-60$ & 50 & $40-60$ & 51 & $41-61$ & 0.396 \\
\hline LDL-C (mg/dl) & 127 & $101-153$ & 125 & $98-146$ & 128 & $112-157$ & 0.450 \\
\hline Triglycerides (mg/dl) & 107 & $76-162$ & 115 & $75-152$ & 107 & $77-177$ & 0.212 \\
\hline Fat mass $(\mathrm{kg})$ & 28.0 & $23.1-36.6$ & 26.2 & $23.0-34.7$ & 31.1 & $23.6-37.3$ & 0.700 \\
\hline Lean mass (kg) & 58.5 & $55.1-65.4$ & 57.8 & $53.5-65.4$ & 58.9 & $56.8-65.3$ & 0.367 \\
\hline AMS score & 28 & $22-37$ & 29 & $22-38$ & 28 & $24-34$ & 0.921 \\
\hline IIEF-EF score & 28 & $22-30$ & 28 & $21-29$ & 28 & $23-30$ & 0.339 \\
\hline
\end{tabular}

Comparisons of baseline characteristics between men in the vitamin D and the placebo group were performed using student's $T$ test

HOMA-IR homeostasis model assessment-insulin resistance, $Q U I C K I$ quantitative insulin sensitivity check index, $A U C$ area under the curve, $H D L-C$ high-density lipoprotein-cholesterol, $L D L-C$ low-density lipoprotein-cholesterol, $A M S$ Aging Male's Symptoms Questionnaire, $I I E F-E F$ International Index of Erectile Function-Erectile Function Questionnaire

${ }^{\mathrm{a}}$ Total testosterone measured by ID-LC-MS/MS

${ }^{\mathrm{b}}$ Total testosterone measured by immunoassay

with vitamin D had developed hypercalcemia at the final study visit.

\section{Discussion}

In this RCT among men with low serum TT concentrations at baseline, we found no significant effect of vitamin D treatment on serum TT levels or secondary end points. When analyses were restricted to men with $25(\mathrm{OH}) \mathrm{D} \mathrm{lev-}$ els $<50 \mathrm{nmol} / 1$, we found a significant increase of SHBG levels after 12 weeks in the placebo group, whereas SHBG levels remained unchanged in the vitamin D group. There was no significant effect on serum TT levels or the remaining secondary outcome parameters in this subgroup.

Our results demonstrating no significant effect on TT concentrations are in line with our previous data from men with normal serum TT concentrations at baseline [17]. Correspondingly, a previous post hoc analysis by Heijboer et al. [21] did not find a significant treatment effect. Heijboer et al. [21] investigated vitamin D effects on TT concentrations in three independent studies involving men with heart failure, male nursing home residents as well as male non-Western immigrants in the Netherlands. In addition, Jorde et al. [22] 
Table 2 Continuous primary and secondary outcome variables at baseline and final follow-up at study end (12 weeks) in study participants with available values at both study visits

\begin{tabular}{lllll}
\hline Maseline visit & \multicolumn{2}{l}{ Study end } & $\frac{\text { Treatment effect }}{\text { Median IQR }}$ & $\begin{array}{l}\text { Between-group differ- } \\
\text { ences with 95\% CI }\end{array}$ \\
\hline
\end{tabular}

Endocrine characteristics

Total testosterone (nmol/l)

Vitamin D $(n=47) \quad 12.7$

Placebo $(n=47) \quad 13.4$

Free testosterone $(\mathrm{ng} / \mathrm{ml})$

Vitamin D $(n=46) \quad 0.081$

Placebo $(n=46) \quad 0.074$

SHBG $(\mathrm{nmol} / \mathrm{l})$

Vitamin D $(n=46) \quad 27.2$

Placebo $(n=47) \quad 31.2$

Free Androgen Index

Vitamin D $(n=46) \quad 45.7$

Placebo $(n=47) \quad 37.2$

Estradiol (ng/ml)

Vitamin D $(n=47) \quad 35.0$

Placebo $(n=46) \quad 34.5$

FSH (mU/ml)

Vitamin D $(n=47) \quad 5$

Placebo $(n=46) \quad 5.5$

$\mathrm{LH}(\mathrm{mU} / \mathrm{ml})$

Vitamin D $(n=47) \quad 3.7$

Placebo $(n=46) \quad 3.7$

Metabolic characteristics

Homeostatic model assessment-insulin resistance

$\begin{array}{llll}\text { Vitamin D }(n=45) & 3.0 & 1.9-4.4 & 2.6 \\ \text { Placebo }(n=44) & 2.9 & 2.0-5.4 & 3.0\end{array}$

Homeostatic model assessment- $\beta$

$\begin{array}{llllcccc}\text { Vitamin D }(n=45) & 160.1 & 108.3-229.9 & 161.3 & 107.4-215.4 & -0.6 & -54.0 \text { to } 52.7 & 0.982 \\ \text { Placebo }(n=44) & 178.7 & 120.5-239.4 & 157.9 & 94.3-239.4 & & & \\ \text { MATSUDA-index } & & & & & & & \\ \text { Vitamin D }(n=45) & 3.5 & 2.2-5.4 & 3.9 & 2.4-6.7 & 0.3 & -1.1 \text { to } 1.7 & 0.647 \\ \text { Placebo }(n=44) & 4.1 & 1.9-7.5 & 3.6 & 2.2-6.5 & & \end{array}$

Quantitative insulin sensitivity check index

\begin{tabular}{|c|c|c|c|c|c|c|c|}
\hline Vitamin $\mathrm{D}(n=45)$ & 0.32 & $0.31-0.35$ & 0.33 & $0.31-0.35$ & -0.01 & -0.03 to 0.01 & 0.365 \\
\hline Placebo $(n=44)$ & 0.33 & $0.30-0.34$ & 0.32 & $0.30-0.35$ & & & \\
\hline \multicolumn{8}{|c|}{ Area under the curve glucose } \\
\hline Vitamin $\mathrm{D}(n=45)$ & 263.0 & $233.8-305.3$ & 245.9 & $217.3-285.3$ & -8.4 & -28.5 to 11.6 & 0.404 \\
\hline Placebo $(n=44)$ & 252.3 & 219.9-293.4 & 264.8 & $223.8-297.0$ & & & \\
\hline \multicolumn{8}{|c|}{ Area under the curve insulin } \\
\hline Vitamin D $(n=45)$ & 128.2 & $89.4-228.3$ & 131.6 & 75.6-207.2 & -12.7 & -69.6 to 44.1 & 0.657 \\
\hline Placebo $(n=44)$ & 138.6 & $65.3-244.4$ & 145.1 & $78.5-220.9$ & & & \\
\hline \multicolumn{8}{|l|}{ Lipids } \\
\hline \multicolumn{8}{|c|}{ Total cholesterol (mg/dl) } \\
\hline Vitamin D $(n=44)$ & 207 & $165-237$ & 192 & $166-228$ & -0.28 & -11 to 11 & 0.960 \\
\hline Placebo $(n=44)$ & 216 & $194-237$ & 211 & $175-238$ & & & \\
\hline \multicolumn{8}{|c|}{ High-density lipoprotein-cholesterol (mg/dl) } \\
\hline Vitamin D $(n=44)$ & 49 & 41-60 & 48 & $40-62$ & -0.88 & -5 to 3 & 0.650 \\
\hline Placebo $(n=44)$ & 51 & $41-61$ & 53 & $43-65$ & & & \\
\hline
\end{tabular}

$\begin{array}{lllll}10.5-15.4 & 12.8 & 10.2-15.5 & -0.188 & -1.50 \text { to } 1.120 .776 \\ 10.7-16.1 & 14.2 & 10.4-16.4 & & \end{array}$

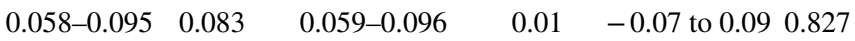

$0.057-0.093$

$19.2-38.1$

$24.7-45.3$

$35.0-56.4$

$28.1-53.1$

$29.0-44.8$

$29.3-46.3$

$4.1-7.4$

$-0.14 \quad-1.1$ to $0.77 \quad 0.755$

$3.3-8.2 \quad 4.3$

$3.2-6.4$

$2.6-6.0$

$0.44-0.48$ to 1.360 .345

$3.2-6.4$

1.9-3.9 $\quad-0.3 \quad-1.0$ to $0.9 \quad 0.955$

$1.7-5.1$

$-1.1 \quad-6.1$ to $3.8 \quad 0.651$

$2.6-4.9 \quad 4.8$

4.3

6

$\begin{array}{lllllll}20.3-38.3 & 28.3 & 19.2-38.1 & -1.7 & -4.2 \text { to } 0.9 & 0.197 \\ 24.4-41.6 & 36.0 & 24.7-45.3 & & & \\ & & & & & \\ 32.5-58.6 & 46.7 & 35.0-56.4 & 2.57 & -3.11 \text { to } 8.25 & 0.371 \\ 28.5-55.4 & 38.4 & 28.1-53.1 & & & \\ & & & & & \\ 26.9-44.2 & 36.0 & 29.0-44.8 & -1.1 & -6.1 \text { to } 3.8 & 0.651 \\ 24.4-42.8 & 34.8 & 29.3-46.3 & & & \\ & & & & & \\ 3.9-6.8 & 5.0 & 4.1-7.4 & -0.14 & -1.1 \text { to } 0.77 & 0.755 \\ 3.3-8.2 & 4.3 & 3.2-6.4 & & & \\ & & & & & \\ 2.6-4.9 & 4.8 & 2.6-6.0 & 0.44 & -0.48 \text { to } 1.36 & 0.345 \\ 2.8-5.7 & 4.3 & 3.2-6.4 & & & \end{array}$

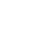


Table 2 (continued)

\begin{tabular}{|c|c|c|c|c|c|c|c|}
\hline & \multicolumn{2}{|c|}{ Baseline visit } & \multicolumn{2}{|c|}{ Study end } & \multicolumn{2}{|c|}{ Treatment effect } & \multirow[t]{2}{*}{$p$ value } \\
\hline & Median & IQR & Median & IQR & $\begin{array}{l}\text { Between } \\
\text { ences wi }\end{array}$ & $\begin{array}{l}\text {-group differ- } \\
\text { th } 95 \% \text { CI }\end{array}$ & \\
\hline \multicolumn{8}{|c|}{ Low-density lipoprotein-cholesterol (mg/dl) } \\
\hline Vitamin D $(n=43)$ & 126 & $98-146$ & 118 & $93-149$ & -0.32 & -10 to 9 & 0.948 \\
\hline Placebo $(n=42)$ & 127 & $106-157$ & 129 & $98-149$ & & & \\
\hline \multicolumn{8}{|l|}{ Triglycerides (mg/dl) } \\
\hline Vitamin D $(n=44)$ & 122 & $78-157$ & 113 & $78-163$ & 10.7 & -10 to 40 & 0.480 \\
\hline Placebo $(n=44)$ & 107 & $78-175$ & 115 & $74-160$ & & & \\
\hline \multicolumn{8}{|l|}{ Body composition } \\
\hline \multicolumn{8}{|l|}{ Fat mass (kg) } \\
\hline Vitamin D $(n=48)$ & 26.2 & $23.2-34.7$ & 26.7 & $22.9-35.1$ & 0.3 & -0.7 to 1.3 & 0.534 \\
\hline Placebo $(n=49)$ & 30.7 & $22.5-37.0$ & 28.9 & $23.5-36.1$ & & & \\
\hline \multicolumn{8}{|l|}{ Lean mass (kg) } \\
\hline Vitamin $\mathrm{D}(n=39)$ & 58.0 & $54.1-65.4$ & 57.9 & $53.7-65.2$ & -0.2 & -0.8 to 0.3 & 0.389 \\
\hline Placebo $(n=37)$ & 58.7 & $56.5-65.3$ & 59.1 & $56.8-63.8$ & & & \\
\hline
\end{tabular}

Treatment effects with 95\% confidence interval and $p$ values were calculated by ANCOVA for group differences at follow-up with adjustment for baseline values. Data are shown as medians and interquartile range

did not find a significant vitamin D effect on TT concentrations in pooled data from three vitamin D RCTs performed in Tromsö with weight reduction, insulin sensitivity, and depression scores as end points. Recently, Zitterman et al. [23] performed a pre-specified secondary analysis of the EVITA (effect of vitamin D on mortality in heart failure) RCT. The authors analyzed the effect of a daily vitamin D supplement of $4000 \mathrm{IU}$ for 3 years $(n=71)$ vs. placebo $(n=62)$ on TT, SHBG, FT, and bioactive T (BAT) in men with $25(\mathrm{OH}) \mathrm{D}$ concentrations $<75 \mathrm{nmol} / \mathrm{l}$. At study end, there was no between-group difference regarding androgen levels and SHBG. Consistently, our findings suggest that previous associations between $25(\mathrm{OH}) \mathrm{D}$ and testosterone status may have been rather the consequence of confounding and/or reverse causation than of a causal effect of vitamin D on testosterone status.

Interestingly, in men with $25(\mathrm{OH}) \mathrm{D}$ levels $<50 \mathrm{nmol} / \mathrm{l}$ at baseline, we observed a significant treatment effect on SHBG, the major carrier protein of testosterone, after 12 weeks of vitamin D supplementation. In detail, SHBG levels remained similar in the vitamin D group, whereas SHBG levels increased in the placebo group. Our findings are difficult to interpret and we cannot exclude that they are caused by chance. As the change in SHBG levels was not accompanied by a change in serum TT or FT levels, the clinical relevance of our finding remains to be determined. Data from men with normal serum TT levels participating the Graz Vitamin D\&TT-RCT suggest a significant decrease of SHBG levels after 3 months in the vitamin D group but not in the placebo group [17]. It should, however, be emphasized that no significant treatment effect was found in eugonadal men [17] and when analyzing an RCT it is the comparison between the two treatment arms, that is of interest. Correspondingly, Zittermann et al. [23] observed no treatment effect on SHBG levels in the EVITA trial. Those different results might be explained by different study duration (3 months vs. 3 years), study participants (healthy men vs. men with advanced heart failure) and vitamin D dosing regimens (20,000 IU/week vs. $4000 \mathrm{IU} /$ day) used in the studies. In this context, it should also be noted that previous observational studies found an inverse association of $25(\mathrm{OH}) \mathrm{D}$ and SHBG levels [16, 24].

Our results regarding varying serum TT levels assessed via immunoassay and ID-LC-MS/MS supports previous statements on the unreliable results of the currently used immunoassays [25] as well as the need for at least two measurements of low TT levels to confirm the diagnosis of hypogonadism [26]. Due to feasibility reasons, we used TT levels measured once by immunoassay to get immediate results, as MS was not available for these measurements at our department. Nevertheless, in light of the large discrepancies between baseline serum TT levels assessed by different methods $(12.7 \mathrm{nmol} / \mathrm{l}$ vs. $8.2 \mathrm{nmol} / \mathrm{l}$ for ID-LC-MS/MS and immunoassay, respectively), the use of ID-LC-MS/MS for measuring TT levels should be considered for evaluation of inclusion criteria in future studies.

Our results in men with normal serum TT levels suggest an adverse effect of vitamin D supplementation on insulin sensitivity [17]. In contrast, in men with low serum TT levels at baseline we found no significant effect on metabolic parameters including insulin sensitivity. Previous evidence on vitamin D and insulin sensitivity is inconsistent. Observational studies point towards a positive association of vitamin $\mathrm{D}$ and insulin sensitivity [2]. Evidence from previous RCTs 
Table 3 Baseline characteristics of study participants with serum 25-hydroxyvitamin D levels $<50 \mathrm{nmol} / 1$ at baseline

\begin{tabular}{|c|c|c|c|c|c|c|c|}
\hline & \multicolumn{2}{|c|}{$\begin{array}{l}\text { All study participants } \\
(n=39)\end{array}$} & \multicolumn{2}{|c|}{ Vitamin D $(n=19)$} & \multicolumn{2}{|c|}{ Placebo $(n=20)$} & \multirow[t]{2}{*}{$p$ value } \\
\hline & Median & IQR & Median & IQR & Median & IQR & \\
\hline Age (years) & 47 & $32-53$ & 46 & $35-52$ & 49 & $32-54$ & 0.858 \\
\hline BMI $\left(\mathrm{kg} / \mathrm{m}^{2}\right)$ & 29.8 & $26.5-34.2$ & 31.2 & $26.5-33.9$ & 29.4 & $26.4-34.3$ & 0.609 \\
\hline 25-Hydroxyvitamin D (nmol/l) & 41 & $35-45$ & 41 & $34-45$ & 41 & $37-44$ & 0.904 \\
\hline PTH (pg/ml) & 49.4 & $42.2-60.8$ & 49.3 & $35.7-65.5$ & 51.1 & $42.4-59.0$ & 0.743 \\
\hline Serum calcium (mmol/l) & 2.36 & $2.31-2.39$ & 2.37 & $2.34-2.44$ & 2.34 & $2.30-2.39$ & 0.060 \\
\hline Urine calcium (mmol/l) & 3.06 & $1.96-4.32$ & 2.57 & $1.19-3.88$ & 3.19 & $2.69-4.44$ & 0.272 \\
\hline Total testosterone ${ }^{\mathrm{a}}(\mathrm{nmol} / \mathrm{l})$ & 12.2 & $9.7-16.2$ & 12.0 & $10.6-16.5$ & 12.3 & $9.6-16.1$ & 0.910 \\
\hline Total testosterone immunoassay $(\mathrm{nmol} / \mathrm{l})^{\mathrm{b}}$ & 8.7 & $7.0-10.0$ & 8.7 & $7.3-10.0$ & 8.8 & $7.0-9.9$ & 0.687 \\
\hline Free testosterone $(\mathrm{ng} / \mathrm{ml})$ & 0.073 & $0.056-0.091$ & 0.071 & $0.058-0.088$ & 0.076 & $0.053-0.093$ & 0.911 \\
\hline SHBG (nmol/l) & 27.4 & $19.5-42.4$ & 27.1 & $16.2-44.4$ & 28.0 & $20.1-42.0$ & 0.559 \\
\hline Free androgen index & 39.1 & $29.0-65.1$ & 39.1 & $29.3-63.6$ & 37.9 & $28.8-66.0$ & 0.789 \\
\hline Estradiol (ng/ml) & 34.5 & $26.4-47.4$ & 34.2 & $26.9-53.4$ & 35.4 & $24.4-41.7$ & 0.239 \\
\hline FSH (mU/ml) & 4.8 & $3.1-6.8$ & 5.0 & $3.3-6.8$ & 3.5 & $2.7-7.7$ & 0.351 \\
\hline LH (mU/ml) & 3.4 & $2.6-4.6$ & 3.4 & $2.6-4.6$ & 3.3 & $2.3-5.6$ & 0.633 \\
\hline HOMA-IR & 3.1 & $2.1-5.4$ & 3.1 & $1.9-5.9$ & 3.2 & $2.2-5.3$ & 0.948 \\
\hline HOMA- $\beta$ & 179.5 & $118.7-251.6$ & 131.4 & $85.0-251.6$ & 196.3 & $137.3-255.0$ & 0.096 \\
\hline MATSUDA-index & 3.9 & $1.9-5.6$ & 3.6 & $2.1-5.3$ & 4.1 & $1.9-5.6$ & 0.689 \\
\hline QUICKI & 0.32 & $0.30-0.34$ & 0.32 & $0.30-0.35$ & 0.32 & $0.30-0.34$ & 0.415 \\
\hline AUCglucose & 261.5 & $222.0-304.5$ & 261.3 & $220.5-312.3$ & 262.0 & $222.0-287.3$ & 0.370 \\
\hline AUCinsulin & 126.8 & $73.9-216.4$ & 125.2 & $89.4-222.4$ & 136.0 & $23.5-210.5$ & 0.961 \\
\hline Total cholesterol (mg/dl) & 215 & $179-233$ & 202 & $166-233$ & 216 & $196-235$ & 0.420 \\
\hline HDL-C (mg/dl) & 49 & $41-61$ & 48 & $42-61$ & 50 & $41-61$ & 0.818 \\
\hline LDL-C (mg/dl) & 130 & $101-145$ & 129 & $101-144$ & 131 & $106-161$ & 0.716 \\
\hline Triglycerides (mg/dl) & 131 & $82-179$ & 129 & 99-174 & 139 & $63-181$ & 0.381 \\
\hline Fat mass $(\mathrm{kg})$ & 31.6 & $25.3-39.9$ & 31.6 & $25.9-39.9$ & 31.3 & $23.9-39.9$ & 0.797 \\
\hline Lean mass (kg) & 58.0 & $55.2-65.4$ & 61.7 & $51.4-65.6$ & 58.0 & $56.4-62.6$ & 0.897 \\
\hline AMS score & 27 & 21-31 & 23 & 19-32 & 28 & $25-31$ & 0.114 \\
\hline IIEF-EF score & 28 & $23-30$ & 28 & $24-30$ & 26 & $23-30$ & 0.671 \\
\hline
\end{tabular}

Comparisons of baseline characteristics between men in the vitamin D and the placebo group were performed using student's $T$ test

HOMA-IR homeostatic model assessment-insulin resistance, $Q U I C K I$ quantitative insulin sensitivity check index, $A U C$ area under the curve, $H D L-C$ high-density lipoprotein-cholesterol, $L D L-C$ low-density lipoprotein-cholesterol, $A M S$ Aging Male's Symptoms Questionnaire, $I I E F-E F$ International Index of Erectile Function-Erectile Function Questionnaire

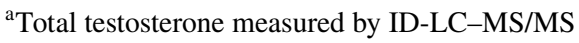

${ }^{\mathrm{b}}$ Total testosterone measured by immunoassay

revealed, however, conflicting results $[27,28]$. A positive vitamin D effect has been demonstrated in insulin-resistant, vitamin D-deficient women [28]. Mousa et al. [27] failed to demonstrate a significant vitamin D effect on insulin sensitivity (determined via hyperinsulinemic/euglycemic clamp) in vitamin D-deficient overweight or obese adults, which is in line with our results. We, therefore, cannot exclude that our previous findings [17] were caused by chance.

Our study has several limitations that should be noted. First, we used TT measured by immunoassay for evaluation of inclusion criteria. As TT levels measured by ID-LC-MS/ MS were higher than expected, we cannot exclude significant vitamin D effects on androgen levels in men with lower TT levels at baseline. Further, as we investigated a cohort of men with relatively high baseline $25(\mathrm{OH}) \mathrm{D}$ levels, we cannot exclude vitamin D effects in men with severe vitamin D deficiency. This notion is supported by the fact that subgroup analyses of men with $25(\mathrm{OH}) \mathrm{D}$ levels $<50 \mathrm{nmol} / \mathrm{l}$ revealed a significant effect on SHBG levels at study end. Given that a U-shaped association of vitamin D levels with hypogonadism has been observed previously, one might speculate that a RCT aiming at target $25(\mathrm{OH}) \mathrm{D}$ levels between 75 and $100 \mathrm{nmol} / \mathrm{l}$ would provide different results. Further, time interval of vitamin D supplementation (daily instead of 
Table 4 Continuous primary and secondary outcome variables at baseline and final follow-up at study end (12 weeks) in study participants with serum 25-hydroxyvitamin D levels $<50 \mathrm{nmol} / \mathrm{l}$ at baseline and with available values at both study visits

\begin{tabular}{lllll}
\hline Median IQR & $\frac{\text { Study end }}{\text { Median IQR }}$ & $\frac{\text { Treatment effect }}{\text { Between-group differ- }}$ \\
ences with 95\% CI
\end{tabular}

Endocrine characteristics

Total testosterone (nmol/l)

Vitamin D $(n=19) \quad 12.0$

Placebo $(n=20) \quad 12.3$

$10.6-16.5$

9.6-16.1

12.7
15.1

$11.7-15.9$

$-0.472$

-3.18 to 2.23

0.725

Free testosterone $(\mathrm{ng} / \mathrm{ml})$

Vitamin D $(n=17) \quad 0.071$

Placebo $(n=18) \quad 0.076$

$0.058-0.088 \quad 0.083$

$0.053-0.093 \quad 0.087$

SHBG $(\mathrm{nmol} / \mathrm{l})$

Vitamin D $(n=17) \quad 27.1$

Placebo $(n=19) \quad 28.0$

$16.2-44.4 \quad 26.9$

$20.1-42.0 \quad 37.0$

Free androgen index

Vitamin D $(n=17) \quad 39.1$

$29.3-63.6 \quad 48.4$

Placebo $(n=19)$

37.9

$28.8-66.0 \quad 40.8$

Estradiol (ng/ml)

Vitamin D $(n=17) \quad 34.2$

Placebo $(n=19) \quad 35.4$

$26.9-53.4 \quad 37.1$

24.4-41.7 34.4

FSH (mU/ml)

Vitamin D $(n=17) \quad 5.0$

Placebo $(n=19) \quad 3.5$

$3.3-6.8 \quad 4.8$

$2.7-7.7 \quad 4.6$

$\mathrm{LH}(\mathrm{mU} / \mathrm{ml})$

Vitamin D $(n=17) \quad 3.4$

$2.6-4.6 \quad 4.4$

Placebo $(n=19) \quad 3.3$

$2.3-5.6 \quad 3.7$

Metabolic characteristics

Homeostatic model assessment-insulin resistance

$$
\begin{array}{llll}
\text { Vitamin } \mathrm{D}(n=16) & 3.1 & 1.9-5.9 & 2.6 \\
\text { Placebo }(n=17) & 3.2 & 2.2-5.3 & 3.0
\end{array}
$$

Homeostatic model assessment $\beta$

$\begin{array}{ll}\text { Vitamin } \mathrm{D}(n=16) & 131.4 \\ \text { Placebo }(n=17) & 196.3\end{array}$

$85.0-251.6 \quad 158.7$

\begin{tabular}{|c|c|c|c|c|c|c|c|}
\hline Vitamin D $(n=14)$ & 3.6 & $2.1-5.3$ & 3.3 & $2.1-6.7$ & -1.0 & -3.6 to 1.7 & 0.449 \\
\hline Placebo $(n=17)$ & 4.1 & $1.9-5.6$ & 4.3 & $2.1-8.1$ & & & \\
\hline \multicolumn{8}{|c|}{ Quantitative insulin sensitivity check index } \\
\hline Vitamin D $(n=16)$ & 0.32 & $0.30-0.35$ & 0.33 & $0.31-0.36$ & -0.02 & -0.07 to 0.02 & 0.258 \\
\hline Placebo $(n=17)$ & 0.32 & $0.30-0.34$ & 0.32 & $0.30-0.38$ & & & \\
\hline
\end{tabular}

$(n=17)$

$137.3-255.0 \quad 146.2$

MATSUDA-index

Area under the curve glucose

Vitamin D $(n=17) \quad 261.3$

Placebo $(n=17) \quad 262.0$

$220.5-312.3 \quad 269.3$

$226.0-277.3-6.3 \quad-36.2$ to $48.8 \quad 0.766$

Area under the curve insulin

Vitamin D $(n=16) \quad 125.2$

Placebo $(n=17) \quad 136.0$

$89.4-222.4 \quad 172.2$

$23.5-210.5 \quad 120.8$

Lipids

Total cholesterol (mg/dl)

Vitamin D $(n=16) \quad 202$

Placebo $(n=19) \quad 216$

166-233 190

196-235 198

High-density lipoprotein-cholesterol (mg/dl)

Vitamin D $(n=16) \quad 48$

42-61 43

$41-61 \quad 53$

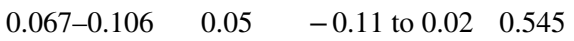

0.063-0.097

$15.4-38.1$

21.9-46.7

41.1-63.0

7.5

-4.3 to 19.3

0.205

28.1-54.5

$27.6-54.8$

3.2

-7.0 to 13.3

0.532

$28.1-46.1$

$4.2-6.6$

0.50

-1.11 to 2.120 .531

$2.5-8.2$

2.3-5.6

1.3

-0.52 to $3.05 \quad 0.160$

3.1-6.4

$1.4-4.1$

0.0

-2.2 to 2.2

0.999

$1.1-5.3$

99.9-227.1

$9.2-83.0$ to $101.5 \quad 0.893$

$59.0-323.8$

$239.5-297.0$

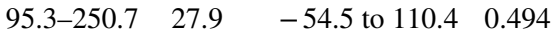

$78.5-197.3$

Placebo $(n=19) \quad 50$
50

53

\section{5-219 $-0.33-17$ to 16 \\ 174-238}

$\begin{array}{llll}39-53 & -4.1 & -9.9 \text { to } 1.7 & 0.163 \\ 40-64 & & & \end{array}$


Table 4 (continued)

\begin{tabular}{|c|c|c|c|c|c|c|c|}
\hline & \multicolumn{2}{|c|}{ Baseline visit } & \multicolumn{2}{|c|}{ Study end } & \multicolumn{2}{|c|}{ Treatment effect } & \multirow[t]{2}{*}{$p$ value } \\
\hline & Median & IQR & Median & IQR & $\begin{array}{l}\text { Betwee } \\
\text { ences } \mathrm{w}\end{array}$ & $\begin{array}{l}\text {-group differ- } \\
\text { th } 95 \% \text { CI }\end{array}$ & \\
\hline \multicolumn{8}{|c|}{ Low-density lipoprotein-cholesterol (mg/dl) } \\
\hline Vitamin D $(n=15)$ & 129 & $101-144$ & 119 & $91-136$ & -0.37 & -15 to 14 & 0.960 \\
\hline Placebo $(n=18)$ & 131 & $106-161$ & 117 & $96-153$ & & & \\
\hline \multicolumn{8}{|l|}{ Triglycerides (mg/dl) } \\
\hline Vitamin $\mathrm{D}(n=16)$ & 129 & $99-174$ & 114 & $83-150$ & 18.6 & -37 to 74 & 0.499 \\
\hline Placebo $(n=19)$ & 139 & $63-181$ & 100 & $64-159$ & & & \\
\hline \multicolumn{8}{|l|}{ Body composition } \\
\hline \multicolumn{8}{|l|}{ Fat mass $(\mathrm{kg})$} \\
\hline Vitamin D $(n=17)$ & 31.6 & $25.9-39.9$ & 31.9 & $26.7-35.4$ & 0.1 & -1.8 to 2.0 & 0.911 \\
\hline Placebo $(n=19)$ & 31.3 & $23.9-39.9$ & 28.9 & $23.6-37.4$ & & & \\
\hline \multicolumn{8}{|l|}{ Lean mass (kg) } \\
\hline Vitamin D $(n=17)$ & 61.7 & $51.4-65.6$ & 60.6 & $53.6-65.3$ & 0.13 & -0.9 to 1.1 & 0.786 \\
\hline Placebo $(n=19)$ & 58.0 & $56.4-62.6$ & 57.8 & $56.8-63.0$ & & & \\
\hline
\end{tabular}

Data are shown as medians and interquartile range. Treatment effects with $95 \%$ confidence interval and $p$ values were calculated by ANCOVA for group differences at follow-up with adjustment for baseline values

Table 5 Parameters of mineral metabolism at baseline and study end (12 weeks)

\begin{tabular}{|c|c|c|c|c|c|c|c|}
\hline & \multicolumn{2}{|c|}{ Baseline visit } & \multicolumn{2}{|c|}{ Study end } & \multicolumn{2}{|c|}{ Treatment effect } & \multirow[t]{2}{*}{$p$ value } \\
\hline & Median & IQR & Median & IQR & $\begin{array}{l}\text { Betwee } \\
\text { ences W }\end{array}$ & $\begin{array}{l}\text {-group differ- } \\
\text { ith } 95 \% \text { CI }\end{array}$ & \\
\hline \multicolumn{8}{|c|}{ 25-Hydroxyvitamin D (nmol/l) } \\
\hline Vitamin D $(n=47)$ & 56 & $44-72$ & 89 & $83-110$ & 32 & 23 to 41 & $<0.001$ \\
\hline Placebo $(n=47)$ & 52 & $42-63$ & 62 & $52-76$ & & & \\
\hline \multicolumn{8}{|l|}{ PTH (pg/ml) } \\
\hline Vitamin $\mathrm{D}(n=46)$ & 45.4 & $35.2-58.0$ & 48.6 & $37.3-60.2$ & -0.9 & -5.7 to 4.0 & 0.727 \\
\hline Placebo $(n=47)$ & 43.1 & $36.3-55.2$ & 49.9 & $37.1-58.2$ & & & \\
\hline \multicolumn{8}{|c|}{ Serum calcium (mmol/l) } \\
\hline Vitamin D $(n=47)$ & 2.37 & $2.32-2.44$ & 2.37 & $2.30-2.44$ & -1.7 & -4.2 to 0.9 & 0.197 \\
\hline Placebo $(n=47)$ & 2.36 & $2.32-2.42$ & 2.36 & $2.29-2.41$ & & & \\
\hline \multicolumn{8}{|c|}{ Urine calcium (mmol/l) } \\
\hline Vitamin D $(n=46)$ & 2.50 & $1.19-3.61$ & 2.15 & $0.96-3.94$ & -0.25 & -0.98 to 0.48 & 0.497 \\
\hline Placebo $(n=46)$ & 2.83 & $1.5-3.63$ & 2.54 & $1.61-3.58$ & & & \\
\hline
\end{tabular}

Data are shown as medians and interquartile range. Treatment effects with $95 \%$ confidence interval and $p$ values were calculated by ANCOVA for group differences at follow-up with adjustment for baseline values weekly doses) as well as the relatively short treatment period might have had an impact on our study outcome. We cannot exclude substantial effects of vitamin D on androgen levels with different doses, time intervals or longer treatment. As we present results from a single-center study performed in healthy middle-aged men with low serum TT levels, our results may not be generalizable to other populations.

Strengths of our study include the study design of an RCT as well as the use of state-of-the-art and standardized methods to measure $25(\mathrm{OH}) \mathrm{D}$ as well as TT concentrations in our samples [26]. Further, we included a relatively large number of participants and the dropout rate was low.

In summary, we found no significant vitamin D effect on androgen levels including TT, FT and FAI concentrations in this cohort of middle-aged healthy men with low baseline serum TT levels. This finding confirms our previous results in men with normal serum TT levels and suggests that vitamin D treatment has no clinical relevant effect on testosterone levels in men. Of note, future studies should only be performed in truly vitamin D-deficient subjects $(<25$ or $30 \mathrm{nmol} / \mathrm{l})$ and low testosterone levels to evaluate vitamin D effects on testosterone levels. 
Table 6 Parameters of mineral metabolism at baseline and study end (12 weeks) in study participants with serum 25-hydroxyvitamin D levels $<50 \mathrm{nmol} / \mathrm{l}$ at baseline $(n=39)$

\begin{tabular}{|c|c|c|c|c|c|c|c|}
\hline & \multicolumn{2}{|c|}{ Baseline visit } & \multicolumn{2}{|c|}{ Study end } & \multicolumn{2}{|c|}{ Treatment effect } & \multirow[t]{2}{*}{$p$ value } \\
\hline & Median & IQR & Median & IQR & $\begin{array}{l}\text { Betwee } \\
\text { ences y }\end{array}$ & $\begin{array}{l}\text {-group differ- } \\
\text { th } 95 \% \text { CI }\end{array}$ & \\
\hline \multicolumn{8}{|c|}{ 25-Hydroxyvitamin D (nmol/l) } \\
\hline Vitamin D $(n=19)$ & 41 & $34-45$ & 86 & $79-95$ & 37 & 27 to 47 & $<0.001$ \\
\hline Placebo $(n=20)$ & 41 & $37-44$ & 54 & $42-62$ & & & \\
\hline \multicolumn{8}{|l|}{ PTH (pg/ml) } \\
\hline Vitamin D $(n=17)$ & 49.3 & $35.7-65.5$ & 45.4 & $30.6-66.1$ & -2.7 & -10.0 to 4.6 & 0.452 \\
\hline Placebo $(n=19)$ & 51.1 & $42.4-59.0$ & 52.0 & $46.0-58.2$ & & & \\
\hline \multicolumn{8}{|c|}{ Serum calcium (mmol/l) } \\
\hline Vitamin $\mathrm{D}(n=17)$ & 2.37 & $2.34-2.44$ & 2.36 & $2.32-2.38$ & -0.1 & -0.1 to 0.1 & 0.969 \\
\hline Placebo $(n=19)$ & 2.34 & $2.30-2.39$ & 2.33 & $2.27-2.39$ & & & \\
\hline \multicolumn{8}{|c|}{ Urine calcium (mmol/l) } \\
\hline Vitamin $\mathrm{D}(n=17)$ & 2.57 & $1.19-3.88$ & 1.43 & $1.11-2.45$ & -1.26 & -2.60 to 0.07 & 0.062 \\
\hline Placebo $(n=19)$ & 3.19 & $2.69-4.44$ & 3.36 & $2.15-5.59$ & & & \\
\hline
\end{tabular}

Data are shown as medians and interquartile range. Treatment effects with $95 \%$ confidence interval and $p$ values were calculated by ANCOVA for group differences at follow-up with adjustment for baseline values

\begin{abstract}
Acknowledgements Open access funding provided by Medical University of Graz. This study was supported by funding from the Austrian National Bank (OeNB Jubilaeumsfonds Project 14846). We thank all study participants. Furthermore, we thank Roswitha Gumpold for recruitment of patients, Cornelia Missbrenner and the Endocrinology Lab platform for continuous support as well as Fresenius Kabi for providing the study medication.
\end{abstract}

\section{Compliance with ethical standards}

Ethical standards All study participants gave written informed consent prior to their inclusion in the study. The study was approved by the ethics committee at the Medical University of Graz, Austria, and was designed to comply with the Declaration of Helsinki.

Conflict of interest The authors declare that they have no conflict of interest.

Open Access This article is distributed under the terms of the Creative Commons Attribution 4.0 International License (http://creativeco mmons.org/licenses/by/4.0/), which permits unrestricted use, distribution, and reproduction in any medium, provided you give appropriate credit to the original author(s) and the source, provide a link to the Creative Commons license, and indicate if changes were made.

\section{References}

1. Holick MF (2007) Vitamin D deficiency. N Engl J Med 357:266-281

2. Pludowski P, Holick MF, Pilz S, Wagner CL, Hollis BW, Grant WB, Shoenfeld Y, Lerchbaum E, Llewellyn DJ, Kienreich K, Soni M (2013) Vitamin D effects on musculoskeletal health, immunity, autoimmunity, cardiovascular disease, cancer, fertility, pregnancy, dementia and mortality - a review of recent evidence. Autoimmun Rev 12:976-989
3. Wehr E, Pilz S, Schweighofer N, Giuliani A, Kopera D, Pieber TR, Obermayer-Pietsch B (2009) Association of hypovitaminosis $\mathrm{D}$ with metabolic disturbances in polycystic ovary syndrome. Eur J Endocrinol 161:575-582

4. Pilz S, März W, Wellnitz B, Seelhorst U, Fahrleitner-Pammer A, Dimai HP, Boehm BO, Dobnig H (2008) Association of vitamin $\mathrm{D}$ deficiency with heart failure and sudden cardiac death in a large cross-sectional study of patients referred for coronary angiography. J Clin Endocrinol Metab 93:3927-3935

5. Pilz S, Kienreich K, Tomaschitz A, Ritz E, Lerchbaum E, Obermayer-Pietsch B, Matzi V, Lindenmann J, März W, Gandini S, Dekker JM (2013) Vitamin D and cancer mortality: systematic review of prospective epidemiological studies anticancer. Agents Med Chem 13:107-117

6. Khaw KT, Dowsett M, Folkerd E, Bingham S, Wareham N, Luben R, Welch A, Day N (2007) Endogenous testosterone and mortality due to all causes, cardiovascular disease, and cancer in men: European prospective investigation into cancer in Norfolk (EPIC-Norfolk) Prospective Population Study. Circulation 116:2694-2701

7. Laughlin GA, Barrett-Connor E, Bergstrom J (2008) Low serum testosterone and mortality in older men. J Clin Endocrinol Metab 93:68-75

8. Wehr E, Pilz S, Boehm BO, März W, Grammer T, ObermayerPietsch B (2011) Low free testosterone is associated with heart failure mortality in older men referred for coronary angiography. Eur J Heart Fail 13:482-488

9. Wehr E, Pilz S, Boehm BO, März W, Grammer TB, ObermayerPietsch B (2010) Sex steroids and mortality in men referred for coronary angiography. Clin Endocrinol (Oxf) 73:613-621

10. Lerchbaum E, Pilz S, Boehm BO, Grammer TB, ObermayerPietsch B, März W (2012) Combination of low free testosterone and low vitamin D predicts mortality in older men referred for coronary angiography. Clin Endocrinol (Oxf) 77:475-483

11. Hofer D, Münzker J, Schwetz V, Ulbing M, Hutz K, Stiegler P, Zigeuner R, Pieber TR, Müller H, Obermayer-Pietsch B (2014) Testicular synthesis and vitamin D action. J Clin Endocrinol Metab 99:3766-3773

12. O'Shaughnessy PJ (2014) Hormonal control of germ cell development and spermatogenesis. Semin Cell Dev Biol 29:55-65 
13. Ramaswamy S, Weinbauer GF (2015) Endocrine control of spermatogenesis: role of FSH and LH/testosterone. Spermatogenesis 4:e996025

14. Kinuta K, Tanaka H, Moriwake T, Aya K, Kato S, Seino Y (2000) Vitamin D is an important factor in estrogen biosynthesis of both female and male gonads. Endocrinology 141:1317-1324

15. Blomberg Jensen MGLJ, Andersson AM, Petersen JH, Nordkap L, Bang AK, Ekbom P, Joensen UN, Prætorius L, Lundstrøm P, Boujida VH, Lanske B, Juul A, Jørgensen N (2014) Vitamin D and male reproduction. Nat Rev Endocrinol 10:175-186

16. Trummer C, Pilz S, Schwetz V, Obermayer-Pietsch BR, Lerchbaum E (2018) Vitamin D, PCOS and androgens in men: a systematic review. Endocr Connect 7:R95-R113 (Epub ahead of print)

17. Lerchbaum E, Pilz S, Trummer C, Schwetz V, Pachernegg O, Heijboer AC, Obermayer-Pietsch B (2017) Vitamin D and testosterone in healthy men: a randomized controlled trial. J Clin Endocrinol Metab 102:4292-4302

18. Dirks NF, Vesper HW, van Herwaarden AE, van den Ouweland JM, Kema IP, Krabbe JG, Heijboer AC (2016) Various calibration procedures result in optimal standardization of routinely used 25(OH)D ID-LC-MS/MS methods. Clin Chim Acta 462:49-54

19. Büttler RM, Martens F, Fanelli F, Pham HT, Kushnir MM, Janssen MJ, Owen L, Taylor AE, Soeborg T, Blankenstein MA, Heijboer AC (2015) Comparison of 7 published LC-MS/MS methods for the simultaneous measurement of testosterone, androstenedione, and dehydroepiandrosterone in serum. Clin Chem 61:1475-1483

20. Vermeulen A, Verdonck L, Kaufman JM (1999) A critical evaluation of simple methods for the estimation of free testosterone in serum. J Clin Endocrinol Metab 84:3666-3672

21. Heijboer AC, Oosterwerff M, Schroten NF, Eekhoff EM, Chel VG, de Boer RA, Blankenstein MA, Lips P (2015) Vitamin D supplementation and testosterone concentrations in male human subjects. Clin Endocrinol (Oxf) 83:105-110
22. Jorde R, Grimnes G, Hutchinson MS, Kjærgaard M, Kamycheva E, Svartberg J (2013) Supplementation with vitamin d does not increase serum testosterone levels in healthy males. Horm Metab Res 45:675-681

23. Zittermann A, Ernst JB, Prokop S, Fuchs U, Dreier J, Kuhn J, Knabbe C, Berthold HK, Gouni-Berthold I, Gummert JF, Börgermann J, Pilz S (2018) Vitamin D supplementation does not prevent the testosterone decline in males with advanced heart failure: the EVITA trial. Eur J Nutr. https://doi.org/10.1007/s0039 4-018-1666-5

24. Wehr E, Pilz S, Boehm BO, März W, Obermayer-Pietsch B (2010) Association of vitamin D status with serum androgen levels in men. Clin Endocrinol (Oxf) 73:243-248

25. Handelsman DJ, Wartofsky L (2013) Requirement for mass spectrometry sex steroid assays in the Journal of Clinical Endocrinology and Metabolism. J Clin Endocrinol Metab 98:3971-3973

26. Bhasin S, Brito JP, Cunningham GR, Hayes FJ, Hodis HN, Matsumoto AM, Snyder PJ, Swerdloff RS, Wu FC, Yialamas MA (2018) Testosterone therapy in men with hypogonadism: an endocrine society clinical practice guideline. J Clin Endocrinol Metab 103:1715-1744

27. Mousa A, Naderpoor N, de Courten MP, Teede H, Kellow N, Walker K, Scragg R, de Courten B (2017) Vitamin D supplementation has no effect on insulin sensitivity or secretion in vitamin D-deficient, overweight or obese adults: a randomized placebocontrolled trial. Am J Clin Nutr 105:1372-1381

28. von Hurst PR, Stonehouse W, Coad J (2010) Vitamin D supplementation reduces insulin resistance in South Asian women living in New Zealand who are insulin resistant and vitamin D deficient - a randomised, placebo-controlled trial. Br J Nutr 103:549-555 